\title{
Identification and Validation of Proteinase 3 and Latent Matrix-Metalloproteinase 9 as Potential Biomarkers for Chronic Lung Transplant Rejection
}

\author{
Yan Zhang • Christine H. Wendt • Marshall I. Hertz • \\ Gary L. Nelsestuen
}

Published online: 5 September 2007

(C) Humana Press Inc. 2007

\begin{abstract}
Introduction This study examined potential biomarkers for the diagnosis and early detection of chronic allograft rejection after lung transplantation.

Methods Protein ratios in pooled samples of bronchoalveolar lavage fluid (BALF) from lung transplant recipients at different stages of pre- and postchronic rejection were determined by iTRAQ labeling and mass spectrometry. The potential biomarkers were validated using enzyme-linked immunosorbent assay (ELISA) assay.

Results Two hundred sixty-five proteins were identified, about two thirds of which showed more than a twofold difference between a pooled control sample (individuals who did not develop chronic rejection in 100 months) and a pooled sample from those with chronic rejection. Proteinase 3 (PR-3) and matrix metalloproteinase 9 (MMP-9) were
\end{abstract}

\author{
Y. Zhang $\cdot$ G. L. Nelsestuen \\ Department of Biochemistry, Molecular Biology and Biophysics, \\ University of Minnesota, \\ Minneapolis, MN 55455, USA \\ Y. Zhang \\ e-mail: zhan0405@umn.edu \\ C. H. Wendt • M. I. Hertz \\ Department of Medicine, Medical School, \\ University of Minnesota, \\ Minneapolis, MN 55455, USA \\ C. H. Wendt \\ e-mail: wendt005@umn.edu \\ M. I. Hertz \\ e-mail: hertz001@umn.edu \\ G. L. Nelsestuen $(\bowtie)$ \\ Room 6-155 Jackson Hall, 321 Church Street S.E., \\ Minneapolis, MN 55455, USA \\ e-mail: nelse002@umn.edu
}

validated by ELISA assay of 124 individual samples. PR-3 and the latent form of MMP-9 (proMMP9) both demonstrated a specificity of $92 \%$ with sensitivities of $76 \%$ and $82 \%$, respectively, for disease diagnosis; both were also predictors of developing chronic rejection up to 15 months before diagnosis. While immunoglobulin $\mathrm{M}(\operatorname{IgM})$ was upregulated in the pooled samples, individual sample analysis revealed that this arose from outlier values.

Conclusions iTRAQ can be used to detect a large number of proteins in pooled samples for the discovery of potential biomarkers, but the findings must be validated with technology capable of distinguishing broadly based changes from outcomes as a result of a few extreme cases. The proteins identified in this study expanded the panel of potential biomarkers for the diagnosis and prediction of chronic rejection and provided additional insight into the mechanism of the disease.

Keywords Lung transplant . Chronic rejection .

Bronchoalveolar lavage fluid (BALF) - Mass spectrometry . Proteomics · Biomarker discovery · Biomarker validation . Bioinformatics

$\begin{array}{ll}\text { Abbreviations } & \\ \text { BALF } & \text { Bronchoalveolar lavage fluid } \\ \text { BOS } & \text { Bronchiolitis obliterans syndrome } \\ \text { MS } & \text { Mass spectrometry } \\ \text { MS/MS } & \text { Tandem mass spectrometry } \\ \text { MALDI-TOF } & \begin{array}{l}\text { Matrix-assisted laser Desorption/ } \\ \text { ionization-time of flight }\end{array} \\ \text { PR-3 } & \text { Proteinase 3 } \\ \text { MMP-9 } & \text { Matrix-metallo proteinase 9 } \\ \text { CCP } & \text { Clara cell protein } \\ \text { HNP } & \text { Human neutrophil peptide } \\ \text { ROC } & \text { Receiver operator characteristic curve } \\ \text { AUC } & \text { Area under curve }\end{array}$




\section{Introduction}

Chronic lung allograft rejection, characterized by inflammation, fibrosis, and proliferation of the small airways, has remained a major obstacle for the long-term survival after lung transplantation $[1,2]$. The five-year survival rate of lung transplant recipients is less than $50 \%$, of which about $30 \%$ is attributed to chronic rejection [1]. Furthermore, about $50-60 \%$ of patients who survive for 5 years beyond lung transplantation are affected by chronic rejection [3]. Chronic rejection is histologically manifested by obliterative bronchiolitis $(\mathrm{OB})$ or clinically as bronchiolitis obliterans syndrome (BOS). At present, BOS is diagnosed by standard lung function tests $[4,5]$, either the progressive decline in forced expiratory volume in $1 \mathrm{~s}$ (FEV1) and/or by mid-expiratory flow rates $\left(\mathrm{FEF}_{25-75}\right)$. Unfortunately, the clinical symptoms of airway obstruction caused by fibroproliferation are irreversible, making discovery of biomarkers for early detection an important goal.

Systematic searches for inflammation and fibrosis mediators in the airways have been reported in lung allograft rejection. Elevated levels of several chemokines from epithelial cells, proteases from neutrophils, and profibrotic cytokines have been associated with BOS [611]. Such targeted studies focus on the effect of one protein or protein family. However, the pathogenesis of BOS involves many complex processes, such as host immunity, alloimmune response, lymphocyte activation, and viral and/ or bacterial infections $[3,12,13]$. An understanding of cellular mechanisms of chronic rejection requires a thorough knowledge of proteins expressed during the process. Broad-based, non-biased searches for protein biomarkers of BOS can expand the base of potential biomarkers and improve our understanding of this disease.

Previous studies used bronchoalveolar lavage fluid (BALF), a widely available source of proteins for studying lung-related diseases [14], and matrix-assisted laser desorption/ionization time-of-flight (MALDI-TOF) mass spectrometry demonstrated human neutrophil defensins, Clara cell protein, lysozyme, and a number of other BALF components as biomarkers for the early detection of chronic lung transplant rejection [15-17]. The results also provided the hypothesis that a major contributor to loss of lung function in BOS was over-activation of the innate immune system. While sensitivity and specificity were excellent, it was clear that additional biomarkers were needed to attain the desired ability to predict BOS well before the onset of clinical symptoms.

Another attractive approach for the comparison of proteins in a complex mixture is iTRAQ technology, a method that uses isobaric tags to label and simultaneously compare up to four samples. Peptides of four different samples are labeled separately with a different reporter group and then mixed before analysis by mass spectrometry. The relative amount of each peptide from the four samples is estimated from the relative intensity of the specific tag applied to each sample. A challenge for virtually all methods that detect proteins by peptide analysis is incomplete coverage of peptides in the mixture. This results in a different set of peptides and proteins identified, even in consecutive runs on the same sample. That is, a second ITRAQ run will yield only partial overlap of peptides identified in the first run. Comparison of the same protein in all samples requires orthogonal methods to validate the ITRAQ findings, such as a quantitative enzyme-linked immunosorbent assay (ELISA) assay.

This study used iTRAQ technology for discovery of additional biomarkers for chronic lung transplant rejection. Biomarkers were then validated by ELISA assay of each sample. Outcomes provided proteinase 3 and MMP-9 as additional biomarkers of BOS. These will contribute to the ultimate development of a panel of biomarkers needed for the accurate prediction of future disease.

\section{Materials and Methods}

Chemicals and Reagents The iTRAQ ${ }^{\mathrm{TM}}$ reagent kit was purchased from Applied Biosystems (Foster City, CA), antibodies for the proteinase 3 (PR-3) ELISA assay were from US Biological (Swampscott, MA), blocking buffer (SuperBlock ${ }^{\mathrm{TM}}$ in Tris buffer) for PR-3 ELISA assay was from Pierce Biotechnology (Rockford, IL), and TMB (3,3',5,5'-Tetramethylbenzidine) substrate for PR-3 ELISA assay was from KPL (Gaithersburg, Maryland). Unless stated, all other chemicals and reagents were purchased from the Sigma Chemical (St. Louis).

BALF Samples The BALF samples were part of the University of Minnesota Lung Transplant Database and O'Brien Biobank. A total of 431 samples were collected from 1993-1996 as a part of routine surveillance of transplant recipients. After the mucus was filtered and the cells were removed by centrifugation, the supernatant was aliquoted and stored at $-80^{\circ} \mathrm{C}$ until use. The studies were approved by the internal review board of the University of Minnesota. Protein analysis of the samples was exempt under federal guidelines 45 CFR part 46.101(b).

All patients who either had been diagnosed with BOS or who developed BOS grade 2 or higher within 100 months after acquiring the BALF samples were included in this study. A similar number of samples from patients who did not develop BOS within 100 months of the sample were also included. A total of 58 individuals and 124 BALF samples were used in this study and were classified in three categories: (1) samples obtained after diagnosis (BOS 
samples, 17 from 7 different patients), (2) samples taken 1 to 15 months before diagnosis of BOS ( preBOS $_{1-15}, 32$ samples from 15 different patients), and (3) samples taken 16 to 76 months before the diagnosis of BOS (preBOS $16-76,27$ samples from 18 individuals). Lung transplant recipients who did not develop BOS within 100 months of sample acquisition were referred to as controls (48 samples from 28 individuals). Table 1 shows the characteristics and clinical information for the patients in the study.

Preparation of BALF Samples The primary objective of this study was to identify biomarkers capable of identifying all preBOS samples from controls. Therefore, we were particularly interested in determining if the preBOS samples that did not have elevated biomarkers previously described (Clara cell protein/lysozyme ratio in MALDITOF) contained other biomarkers of disease. Consequently, the study focused on preBOS $1-15$ samples along with controls and BOS for comparison. The general workflow of the iTRAQ analysis is shown in Fig. 1. iTRAQ analysis required at least $25 \mu \mathrm{g}$ of protein after removal of abundant proteins. Pooled samples provided sufficient volume and protein concentration. Pool one was from controls $(n=16)$, pool 2 was from BOS samples $(n=3)$, pool 3 was from preBOS $_{1-15}$ samples that were correctly identified as preBOS by the Clara cell protein/lysozyme ratio in

Table 1 Characteristics of lung transplant patients in this study

\begin{tabular}{|c|c|c|c|c|}
\hline Category & Controls & $\begin{array}{l}\text { Post- } \\
\text { BOS }\end{array}$ & $\begin{array}{l}\text { Pre- } \\
\text { BOS }_{1-15}\end{array}$ & Pre-BOS ${ }_{16-76}$ \\
\hline Samples $(N)$ & 48 & 17 & 32 & 27 \\
\hline Individuals $(N)$ & 28 & 8 & 15 & 18 \\
\hline Female $(\%)$ & 48 & 50 & 53 & 59 \\
\hline Age $(\operatorname{Avg} \pm \mathrm{STD})$ & $\begin{array}{c}44.8 \pm \\
9.1\end{array}$ & $\begin{array}{c}51.9 \pm \\
9.7\end{array}$ & $\begin{array}{c}47.7 \pm \\
9.0\end{array}$ & $47.2 \pm 9.5$ \\
\hline $\begin{array}{c}\text { Month_After_TX } \\
(\text { Avg } \pm \text { STD })\end{array}$ & $12 \pm 12$ & $26 \pm 17$ & $16 \pm 18$ & $7 \pm 5$ \\
\hline \multicolumn{5}{|c|}{ Reasons for transplant [34] } \\
\hline $\begin{array}{l}\text { Alpha-1-antripysin } \\
\text { deficiency }\end{array}$ & 6 & 3 & 3 & 3 \\
\hline Bronchiectasis & 1 & & & \\
\hline COPD/emphysema & 9 & 2 & 5 & 4 \\
\hline Cystic fibrosis & 5 & & 1 & \\
\hline $\begin{array}{l}\text { Primary pulmonary } \\
\text { hypertension }\end{array}$ & 2 & & 1 & 5 \\
\hline $\begin{array}{l}\text { Eisenmenger's } \\
\text { syndromes }\end{array}$ & 2 & & 2 & 1 \\
\hline $\begin{array}{l}\text { Idiopathic pulmonary } \\
\text { fibrosis }\end{array}$ & 1 & 1 & 1 & 1 \\
\hline $\begin{array}{l}\text { Obliterative } \\
\text { bronchiolitis }\end{array}$ & 1 & & & 1 \\
\hline Lung Re-Tx & & 1 & 2 & 1 \\
\hline Not defined & 1 & 1 & & 2 \\
\hline
\end{tabular}

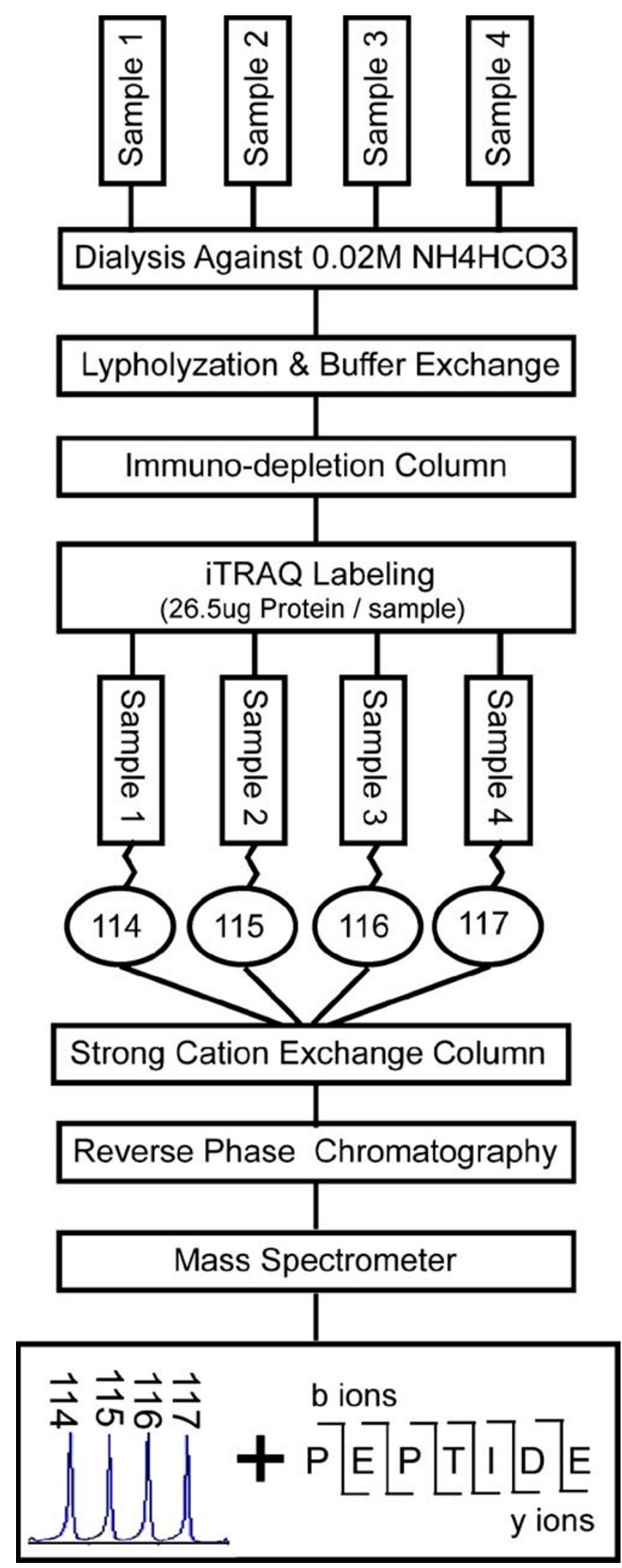

Fig. 1 Sample flow and analysis by iTRAQ technology 
MALDI-TOF protein profile analysis [16] (true positive samples, $n=6$ ), and pool four was from preBOS ${ }_{1-15}$ samples that were not identified by Clara cell to lysozyme ratio analysis in the MALDI-TOF profile (false negatives, $n=6$ ).

The pooled samples were each dialyzed against $4 \mathrm{~L}$ of buffer $\left(0.02 \mathrm{M} \mathrm{NH}_{4} \mathrm{HCO}_{3}, \mathrm{pH}\right.$ 7.7) for $4 \mathrm{~h}$ at room temperature and then overnight at $4^{\circ} \mathrm{C}$ against fresh buffer. The samples were lyophilized and dissolved in $400 \mu \mathrm{L}$ of immunodepletion buffer A (Agilent, Wilmington, DE). The six most abundant plasma proteins (Albumin, IgG, immunoglobulin A (IgA), transferrin, haptoglobin, and $\alpha-1-$ antitrypsin) were removed by passage of the sample through the multiple affinity depletion column $(50 \times 4.6 \mathrm{~mm}$, Agilent). Each sample was split into halves for sequential application to the column. Protein concentrations were measured by the Bradford reagent (BioRad). Samples were examined by $15 \%$ mini-SDS-PAGE (BioRad), and an additional depletion cycle was applied if serum albumin was detected. The final proteins were buffer exchanged into deionized water by ultrafiltration with Micron centrifuge tubes (cutoff $=5 \mathrm{~K}$, Millipore, Bedford, MA).

Equivalent amounts of protein $(26.5 \mathrm{ug})$ from each of the four samples were subjected to trypsin digestion and iTRAQ labeling as outlined in the manufacturer's protocol. Briefly, disulfides were reduced, alkylated, and samples were trypsin-digested. Each sample was labeled with one of the four isobaric iTRAQ reagents with reporter masses of 114, 115,116 , and 117, respectively. The samples were pooled, and the resulting mixture speed vacuumed to dryness, dissolved in deionized water, and purified by adsorption and elution from a Sep-Pak C18 cartridge using standard methods (Waters Corporation, Milford, MA). The recovered peptide mixture was speed-vacuumed to dryness and dissolved in $350 \mu \mathrm{l}$ of strong cation exchange (SCX) loading buffer [20\% $(v / v)$ acetonitrile, $\left.5 \mathrm{mM} \mathrm{KH}_{2} \mathrm{PO}_{4}, \mathrm{pH} 3.2\right]$ for subsequent fractionation.

The first dimension of separation used a SCX polysulfoethyl A column $(150 \times 1.0 \mathrm{~mm}, 5 \mu \mathrm{m}, 300 \AA$, The Nest Group, Southborough, MA) mounted on a Magic 2002 HPLC system (Michrom Bioresources, Auburn, CA). The iTRAQ-labeled mixture was applied to the column at a flow rate of $100 \mu \mathrm{l} / \mathrm{ml}$. Peptides were eluted with a linear gradient of 0 to $20 \%$ elution buffer [20\% $(v / v)$ acetonitrile, $\left.5 \mathrm{mM} \mathrm{KH} \mathrm{KO}_{4}, 500 \mathrm{mM} \mathrm{KCl}, \mathrm{pH} 3.2\right]$ over $40 \mathrm{~min}$ followed by a linear $20-100 \%$ gradient over $20 \mathrm{~min}$. The elution buffer was maintained at $100 \%$ for $10 \mathrm{~min}$ and then returned to the loading buffer for $5 \mathrm{~min}$. Fractions were collected at 2.5-min intervals. Peptide fractions were dried by speed vacuum, and fractions 10 through 28 were dissolved in $30 \mu \mathrm{l}$ of reverse phase loading buffer [98:2, $\mathrm{H}_{2} \mathrm{O} / \mathrm{ACN}, 0.1 \%$ triflouroacetic acid (TFA)]. Each fraction was then desalted with an LCP C18 nano-precolumn
$(5 \times 0.3 \mathrm{~mm})$; they were eluted at $350 \mathrm{nl} / \mathrm{min}$ using an LCP ultimate LC system (Dionex Company, Sunnyvale, CA) and further separated on a reverse-phase C18 column $(13 \mathrm{~cm} \times 5 \mu \mathrm{m}, 200 \AA$ pore size, Michrom BioResources, Auburn, CA), which was coupled online to a QuadrupoleTOF mass spectrometer (QSTAR Pulsar I, Applied Biosystems, Foster City, CA) equipped with Protana's nanoelectrospray source. Peptides were eluted with three stages of linear gradient consisting of $0-30 \%$ solvent B (5:95, $\mathrm{H}_{2} \mathrm{O} / \mathrm{ACN}, 0.1 \%$ formic acid) over $0-35 \mathrm{~min}, 30-45 \%$ solvent B from 35-45 min, and 45-50\% solvent B from 45 to $50 \mathrm{~min}$. Solvent A was $5 \% \mathrm{ACN}$ in $0.1 \%$ formic acid.

The eluted peptides were subjected to in-line mass spectrometry analysis. The product ion spectra were collected in an IDA mode (information-dependent acquisition mode), which included continuous cycles of a 1.5-s full scan (TOF MS from $400-1,100 \mathrm{~m} / \mathrm{z}$ ) followed by product ion scans of the three most intense ions (50-2000 m/z, $3 \mathrm{~s}$ each). During the ion collection process, the instrument's rolling collision energy feature was used to determine collision energy based on precursor $\mathrm{m} / \mathrm{z}$ value and charge state. The electro-spray voltage was $2,250 \mathrm{~V}$, the TOF region acceleration voltage was $4 \mathrm{kV}$, and the injection pulse repetition rate was $6.0 \mathrm{kHz}$. The machine was calibrated using the $[\mathrm{M}+3 \mathrm{H}]^{3+}$ and $[\mathrm{M}+2 \mathrm{H}]^{2+}$ monoisotopic peaks of human renin substrate tetradecapeptide $(\mathrm{m} / \mathrm{z}=586.9830$ and 879.9705 , SigmaAldrich, St. Louis, MO).

Data Handling and Analysis Peptide identification and relative quantification of peptides were performed using ProQuant software (Applied Biosystems, version 1.0). Fragment ion spectra were searched against the Celera human database (human-KBMS3.0.20040121 generated fall, 2004) with the Interrogator ${ }^{\mathrm{TM}}$ algorithm and a 0.35 Da mass tolerance for both parent (MS) and fragment ions (MS/MS). ProGroup viewer (Applied Biosystems, version 1.0.6) was used to generate compiled protein identification and quantification results from the ProQuant database for peptides with a ProScore of greater than 1.3 or $95 \%$ confidence of peptide identification. This approach assumes that peptides represent proteins in the fluid and are referred to as such. It is recognized that this interpretation assumed that only intact proteins were present in BALF. It also does not consider post-translational protein modifications. While proteins identified by more than one peptide and with a software-generated error factor of less than 2.0 were considered optimum (manufacturer's description), proteins identified by a single peptide were used for subsequent validation by ELISA assay.

ELISA Assays ELISA kits for immunoglobulin M (IgM), lysozyme, proMMP-9, and active MMP-9 were purchased from Bethyl Laboratories (Montgomery, TX), ALPCO 
Diagnostics (Salem, NH), EMD Biosciences (San Diego, CA), and R\&D systems (Minneapolis, MN), respectively. These ELISA assays were conducted following the manufacturers' protocol, and data were analyzed with fourparameter nonlinear regression using Prism (GraphPad Software, version 4.0b).

The ELISA assay of proteinase 3 was constructed inhouse following the supplier's protocol for assay set-up. Highly purified human PR-3 antibody from the supplier was reconstituted in $2 \mathrm{ml}$ distilled water and diluted 100 times in coating buffer (50 mM Tris buffer, $\mathrm{pH} 8.0$ ). Ninety-six well ELISA plates (MediSorp ${ }^{\text {TM }} 96$ well ELISA plate, Nunc, Rochester, NY) were coated by adding $100 \mu \mathrm{l}$ of diluted human PR-3 antibody and incubation for $1 \mathrm{~h}$. After the plate was washed three times with washing buffer (50 mM Tris buffer, $\mathrm{pH} 8)$, blocking buffer $(25 \%$ superblock buffer in $0.15 \mathrm{mM}$ saline, $200 \mu \mathrm{l}$ ) was added to each well, and the plate was incubated for $1 \mathrm{~h}$ at room temperature. Following another wash step, PR-3 serial standards (US Biological, Swampscott, MA, 0 to $500 \mathrm{ng} /$ $\mathrm{ml})$ and diluted BALF samples in blocking buffer $(100 \mu \mathrm{l})$ were transferred to the assigned wells, and the plate was incubated for $1 \mathrm{~h}$ at room temperature. After another wash step, $100 \mu \mathrm{l}$ of mouse anti-human proteinase 3 antibody $(0.4 \mu \mathrm{g} / \mathrm{ml})$ were added to each well followed by 1 $h$ incubation and another wash step. Horseradish peroxidase (HRP)-conjugated rabbit anti-mouse IgG $(100 \mu \mathrm{l}, 0.1 \mu \mathrm{g} /$ $\mathrm{ml}$ ) was transferred to each well and incubated for $1 \mathrm{~h}$. After a thorough washing, $100 \mu \mathrm{l}$ of TMB (3,3',5,5'tetramethylbenzidine) substrate was added, and the reaction was stopped after a 20 -min incubation in the dark by addition of $100 \mu \mathrm{l}$ of stopping solution $\left(2 \mathrm{M} \mathrm{H}_{2} \mathrm{SO}_{4}\right)$. The absorbance was measured at $450 \mathrm{~nm}$ using an Elx8000 plate reader (BioTek Instruments, Winooski, VT). All of the antibodies were purchased from US Biological (Swampscott, MA). All steps were conducted at room temperature.

All ELISA data represent average and standard deviation of triplicate measurements. The protein concentrations measured using ELISA assays were analyzed by Prism software nonlinear regression analysis. The concentrations of the target proteins were normalized to total protein, to lysozyme concentration in each sample, or to volume of sample assayed. Statistical analyses were conducted in either Microsoft Excel or R program.

\section{Results}

Relative Protein Quantification of BALF Proteins by ITRAQ Pooled samples consisted of controls (samples from subjects who did not develop BOS within 100 months of the sample), disease (samples from subjects post-diagnosis of BOS), and pre-disease. The latter group included two types: samples from individuals that were collected 115 months before BOS who were accurately predicted by existing biomarkers [true (+), Table 2] and samples from individuals that were collected 1-15 months before BOS who were not detected by the existing biomarkers [false $(-)$, Table 2]. The iTRAQ analysis resulted in confident $(>95 \%)$ identification of peptides from 265 proteins. Of these, 117 proteins were identified by more than two peptides and quantified with an error factor less than 2.0 as assessed by the software program. These criteria are accepted for determination of a protein ratio on the basis of mass spectrometry data alone.

The current study used mass spectrometry for discovery of candidate biomarkers but used other methods for validation. For example, in the absence of corroborating results, protein ratios determined by a single peptide are not considered accurate. However, follow-up analysis by a separate method such as ELISA allows the use of proteins identified by only one peptide, as the second method effectively detects false detection in the iTRAQ experiment. For this reason, we utilized all 265 potential proteins to identify targets for subsequent analysis.

The criterion used to identify proteins for additional study was greater than a threefold change in all categories of disease and pre-disease relative to controls. Table 2 shows a list of these proteins along with their molecular function, biological process, and relative protein ratios. These results suggested that diagnosis of disease could be accomplished by analysis of a very large portion of the proteins identified. However, the target group was pre-BOS that gave false negative results for biomarkers found in previous studies.

Proteins that met the primary criterion included cell surface and cell matrix proteins, cytoskeleton proteins, surfactants, and antimicrobial peptides. These were not immediately targeted because they were considered to be evidence of cell destruction, a process known to occur in BOS, or were identified as house-keeping proteins or correlated with other antimicrobial peptides, such as human neutrophil peptide (HNP), that we documented in a previous study. The proteins of greatest interest were those that might be responsible for cellular destruction such as proteinase 3 and metalloproteinase 9. IgM gave a large change that may also represent a unique immune response. Therefore, these proteins were targeted for further study.

An unidentified protein (accession number dbj|BAC86931.1) was also up regulated in disease. Validity was not highly certain, as it was identified by a single peptide. Furthermore, functional information as well as antibodies for this protein were lacking. Overall, additional information would be required to warrant expenditure of the effort required for analysis by ELISA or other quantitative method. 
Table 2 Partial protein list from iTRAQ

\begin{tabular}{|c|c|c|c|c|c|c|c|}
\hline ID & Accession & Protein name & $\begin{array}{l}\text { Molecular } \\
\text { function }\end{array}$ & $\begin{array}{l}\text { Number of } \\
\text { peptides }\end{array}$ & $\begin{array}{l}\text { BOS/ } \\
\text { CON }\end{array}$ & $\begin{array}{l}\text { False }(-) / \\
\text { CON }\end{array}$ & $\begin{array}{l}\text { True }(+) / \\
\text { CON }\end{array}$ \\
\hline 1 & gb|AAM97934.1 & Matrix metalloproteinase 9 & Protease & 9 & 14.5 & 3.2 & 10.4 \\
\hline 2 & $\mathrm{gb} \mid \mathrm{AAB} 59493.1$ & Proteinase 3 & Protease & 1 & 124.6 & 59.9 & 26.0 \\
\hline 3 & rf|NP_000886.1 & Leukotriene A4 hydrolase & Hydrolase & 1 & 6.8 & 3.0 & 3.2 \\
\hline 4 & $\operatorname{trm} \mid \mathrm{Q} 12760$ & Glutathione S-transferase & Transferase & 1 & 0.1 & 0.3 & 0.1 \\
\hline 5 & $\operatorname{trm} \mid \mathrm{Q} 8 \mathrm{~N} 8 \mathrm{~T} 4$ & Hypothetical protein FLJ38902 & Transcription factor & 1 & 0.2 & 0.3 & 0.3 \\
\hline 6 & $\operatorname{trm} \mid \mathrm{Q} 8 \mathrm{WWQ5}$ & Mucin 5 & Extracellular matrix & 21 & 6.2 & 3.0 & 3.4 \\
\hline 7 & rf|XP_039877.6 & Mucin 5B precursor & Extracellular matrix & 20 & 4.9 & 4.0 & 3.0 \\
\hline 8 & $\mathrm{gb} \mid \mathrm{AAA} 88083.1$ & Hexabrachion & Extracellular matrix & 1 & 18.0 & 4.1 & 3.6 \\
\hline 9 & $\mathrm{gb} \mid \mathrm{AAF} 35390.1$ & Voltage-gated sodium channel alpha subunit & Ion channel & 1 & 6.5 & 3.3 & 7.9 \\
\hline 10 & $\operatorname{pir} \mid \mathrm{A} 61231$ & Myosin heavy chain nonmuscle form A & Cytoskeletal protein & 7 & 3.9 & 3.9 & 4.4 \\
\hline 11 & spt|Q9UIF3 & Tektin 2 & Cytoskeletal protein & 1 & 5.1 & 10.1 & 4.0 \\
\hline 12 & spt|P05107 & Integrin beta-2 precursor & Receptor & 1 & 9.0 & 5.0 & 7.0 \\
\hline 13 & $\operatorname{trm} \mid \mathrm{Q} 9 \mathrm{BTR} 2$ & Mesothelin & Cell adhesion & 4 & 0.1 & 0.3 & 0.2 \\
\hline 14 & pdb|1PW9_A & Human lung surfactant, A chain A & Defense/immunity & 4 & 0.2 & 0.2 & 0.1 \\
\hline 15 & pdb|1MHL_C & Myeloperoxidase isoform C & Oxidoreductase & 24 & 4.7 & 3.0 & 4.5 \\
\hline 16 & rf|NP_004659.1 & Maltase-glucoamylase & Hydrolase & 2 & 6.0 & 3.9 & 6.2 \\
\hline 17 & $\mathrm{dbj} \mid \mathrm{BAC} 86931.1$ & Unnamed protein product & & 1 & 38.4 & 24.0 & 26.6 \\
\hline 18 & $\operatorname{prf} \mid 1617124 \mathrm{~A}$ & Cationic antimicrobial protein CAP37 & Protease & 5 & 16.1 & 5.5 & 10.4 \\
\hline 19 & rf|NP_004336.1 & Cathelicidin antimicrobial peptide & Defense/immunity & 2 & 6.0 & 8.8 & 4.7 \\
\hline 20 & pdb|1ADQ_L & Igm rheumatoid factor Fab, L chain & Defense/immunity & 2 & 7.8 & 13.6 & 14.7 \\
\hline
\end{tabular}

Validation of Biomarkers by ELISA The 124 individual BALF samples were subjected to ELISA assay for quantification of the potential biomarkers. The medians and $25-75 \%$ quartile results for IgM, lysozyme, PR-3, the latent form MMP-9 (proMMP-9), and the active MMP-9 (aMMP-9) from the individual lavage samples are given in Table 3.

Controls (those who did not develop chronic rejection) showed very similar levels of PR-3 (Fig. 2a). However, levels started to increase a few months before the diagnosis of BOS, and a high concentration was maintained for at least 15 months after diagnosis. As a result, PR-3 in samples with chronic rejection (median $=1,337 \mathrm{ng} / \mathrm{mg}$, inter-quartile range (IQR), from 735 to $4,106 \mathrm{ng} / \mathrm{mg}$ ) was significantly higher than that of controls (median $=152 \mathrm{ng} / \mathrm{mg}$, IQR of 65 to $246, p<0.0001$; Table 3 ).

MMP-9 exists in two forms: latent (proMMP-9, $92 \mathrm{kD}$ ) and active (aMMP-9, $85 \mathrm{kD}$ ). The active form arises from cleavage of the amino-terminal domain (propeptide domain) from the latent form. Latent MMP-9 was dramatically higher in samples with chronic rejection (median= $837 \mathrm{ng} / \mathrm{mg}$, IQR of 279 to $3,058 \mathrm{ng} / \mathrm{mg}$ ) than in controls (median=12.7 ng/mg, IQR of 4.68 to $64.7, p<0.0001$, Table 3). In addition, a significant increase of proMMP-9 was found preBOS ${ }_{1-15}$ (Fig. 2b). Greater than 15 months before BOS, proMMP-9 was present at approximately the same level as controls. Surprisingly, aMMP-9 showed a relatively stable level across different BOS stages (Table 3).
For IgM, iTRAQ analysis indicated more than sevenfold difference between disease and control samples $(p=0.002)$. This difference, however, arose largely from three samples in the disease group that had extremely high readings. Significance was lost if the three extreme samples were excluded from statistical comparisons (not shown). In addition, no significant difference was found for $\operatorname{IgM}$ in control vs any preBOS group (Table 3 ).

Different Methods of Normalization BALF is a heterogeneous fluid that is expected to vary in content depending on the region of the lung extracted, mixing of the fluid during the procedure, and other technical factors. It can also vary with the actual protein content of the lung fluid. This raises the question of the appropriate method of biomarker normalization. Concentration can be expressed as a function of total protein in the extract, on the basis of volume of fluid or by comparison to an internal protein marker. Lysozyme remained relatively constant in BALF fluid as judged by mass spectrometry methods (Fig. 3a) conducted with a constant amount of protein. ELISA analysis also showed consistency in disease vs controls when lysozyme was expressed as a function of protein concentration (Fig. 3a). This resulted in a lack of diagnostic power for lysozyme (Fig. 3a) but provided a stable internal standard for comparison to other biomarkers.

Figure $3 \mathrm{~b}$ showed that disease correlated with higher protein concentrations in BALF, making total protein a 
Table 3 Summary of ELISA results indicated as median (25\%, $75 \%$ quartile)

\begin{tabular}{|c|c|c|c|c|c|c|c|}
\hline & Number of samples & IgM (ug/mg) & $\begin{array}{l}\text { Lysozyme } \\
\text { (ug/mg) }\end{array}$ & PR-3 (ng/mg) & $\begin{array}{l}\text { proMMP-9 } \\
\text { (ng/mg) }\end{array}$ & $\begin{array}{l}\text { aMMP-9 } \\
\text { (ng/mg) }\end{array}$ & $\begin{array}{l}\text { aMMP-9 } \\
\text { (ng/ml) }\end{array}$ \\
\hline Control & 48 & $0.96(0.37,1.85)$ & $\begin{array}{l}6.32(3.55, \\
12.1)\end{array}$ & $152(65,246)$ & $12.7(4.68,64.7)$ & $\begin{array}{l}11.1(3.45, \\
33.2)\end{array}$ & $0.53(0.18,1.21)$ \\
\hline $\operatorname{PreBOS}_{16-76}$ & 27 & $0.75(0.35,1.54)$ & $\begin{array}{l}3.47(1.74, \\
8.73)\end{array}$ & $36(15,243)$ & $19.6(2.31,58.2)$ & $\begin{array}{l}19.3(8.83 \\
38.0)\end{array}$ & $0.97(0.17,1.71)$ \\
\hline PreBOS $_{1-15}$ & 32 & $1.31(0.41,3.44)$ & $\begin{array}{l}4.88(2.68, \\
8.98)\end{array}$ & $247(33,1,543)$ & $112(13.2,508)^{* * *}$ & $\begin{array}{l}9.33(3.09, \\
26.8)\end{array}$ & $1.83(0.53,2.99)^{* *}$ \\
\hline BOS & 17 & $2.35(0.59,5.18)^{* *}$ & $\begin{array}{l}6.47(3.20, \\
11.2)\end{array}$ & $1,337(735,4,106)^{*}$ & $837(279,3058) *$ & $\begin{array}{l}20.2(9.09 \\
23.8)\end{array}$ & $2.25(0.79,3.16)^{* *}$ \\
\hline
\end{tabular}

Significance test between BOS and control group.

$* p<0.0001$

$* * p<0.01$

$* * * p<0.05$

biomarker with modest diagnostic power (Fig. 3b). As a result, analysis of biomarkers on the basis of total protein, on the basis of biomarker ratio to lysozyme concentration or on the basis of BALF volume resulted in different outcomes.

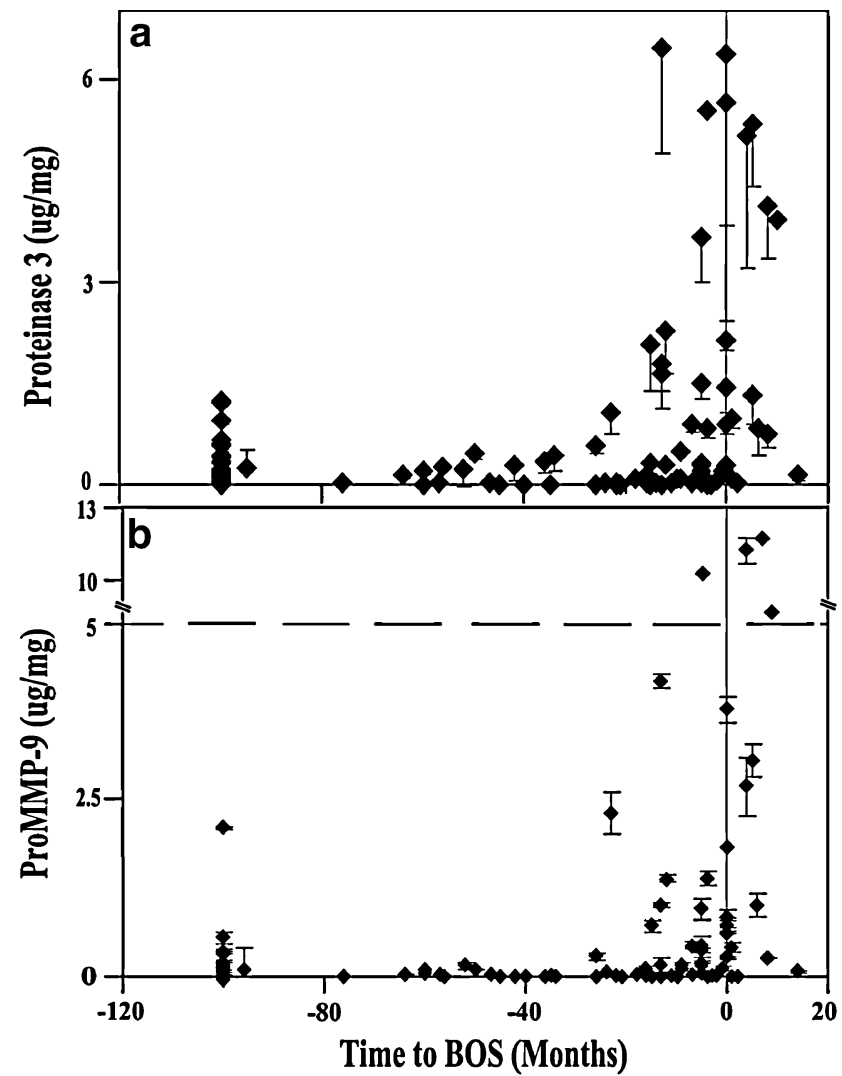

Fig. 2 Biomarker changes as a function of time to diagnosis of BOS. a Proteinase 3. Diagnosis of BOS was assigned time zero. Controls are those without BOS for at least 100 months (shown at -100) from the time of sample collection. One sample at $67 \mathrm{ug} / \mathrm{mg}$ at -15 months to BOS is not shown. b Latent form of MMP-9 (ProMMP-9). Four samples with very high readings are presented in a condensed scale. In both panels, the average and standard deviation of three assays is shown
ROC curve analysis for biomarkers normalized to volume $(/ \mathrm{ml})$, total protein $(/ \mathrm{mg}$ total protein), or to lysozyme level (/mg lysozyme) are compared in Fig. 4. As expected from the results in Fig. 3, biomarker concentration normalized to lysozyme, or volume showed better outcomes than biomarker concentrations normalized to total protein.
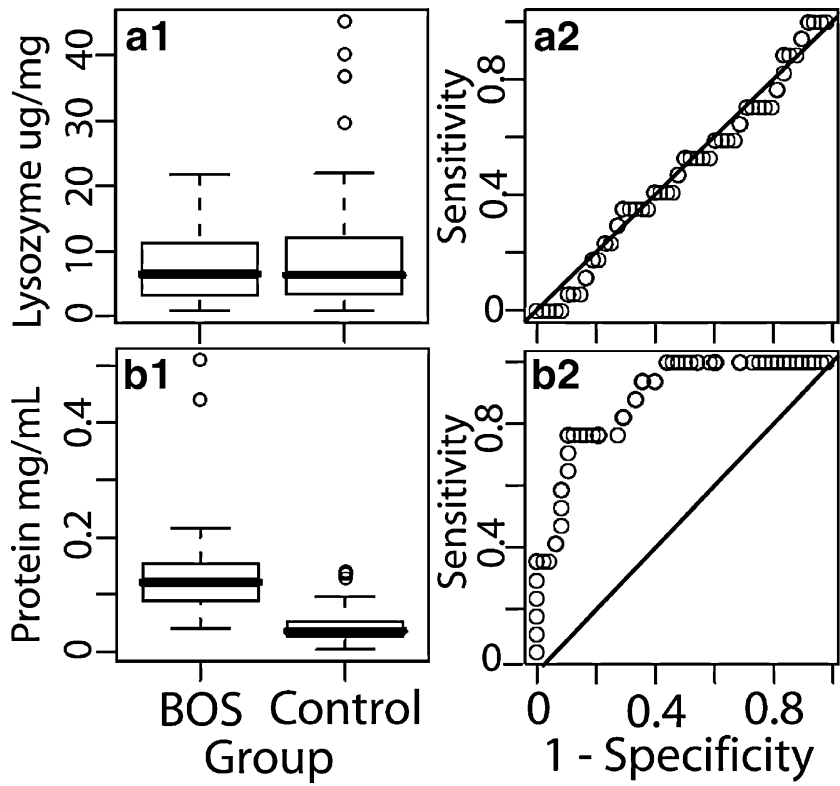

Fig. 3 Distribution and ROC curves for lysozyme and total protein. a Lysozyme. The concentration distribution (al) and ROC curve analysis (a2) is shown for lysozyme when normalized to the total protein. b Protein concentration distribution $(\mathbf{b} 1)$ and ROC curve (b2) for protein concentration in BALF. In both panels, the distributions of biomarkers are illustrated in a box plot $(\mathbf{a} 1 / \mathbf{b} 1)$. The bold horizontal line in the middle of the box indicates the median value. The upper and lower hinges of the box indicate the 25th and 75th percentile values. The experimental points outside of the box indicate the extreme values in that group, and the dashed lines connected to the box indicate the minimum or the maximum value in the dataset. The curves were constructed from data for BOS and control samples 


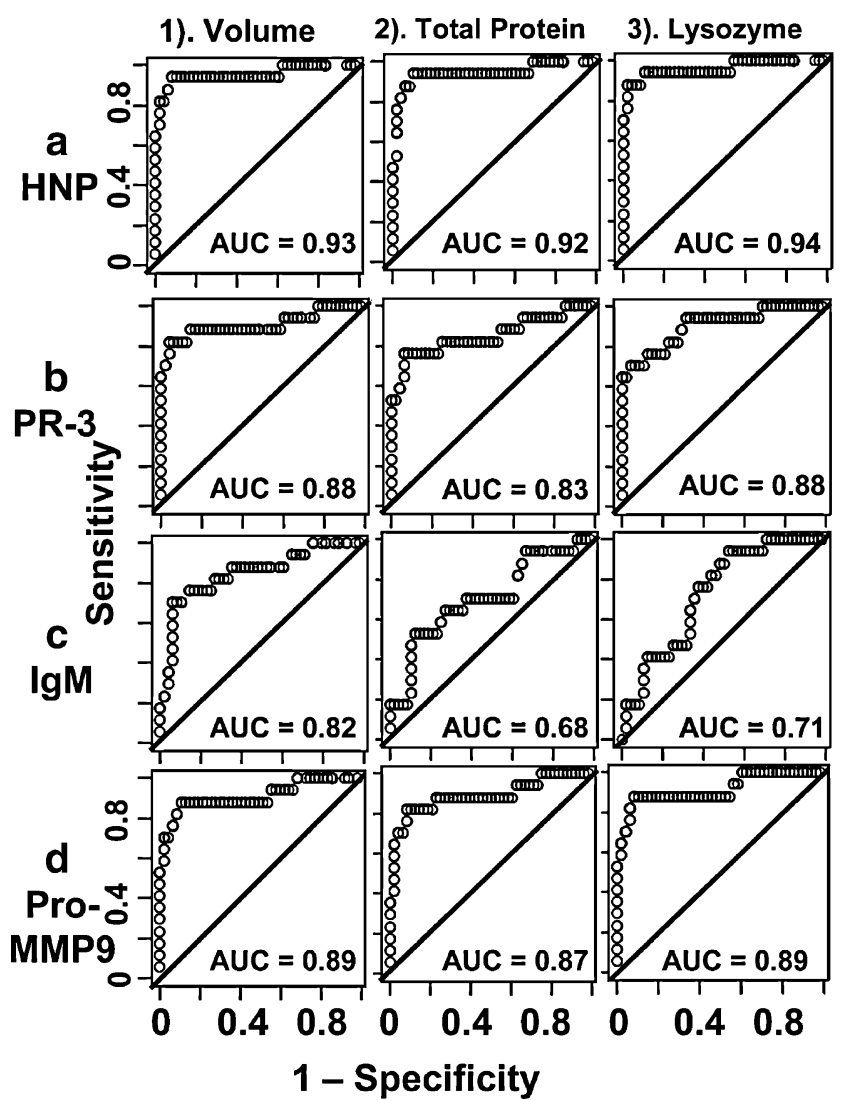

Fig. 4 ROC curve analysis of HNP, PR-3, IgM, and proMMP-9 normalized to various standards. The ROC curve analysis was performed for biomarker concentrations normalized to volume of BALF assayed (analysis marked 1), total protein (analysis marked 2), and lysozyme content (analysis marked 3) of BALF. a Human neutrophil defensins $(H N P)$. Data were from a previous study 17 . b Proteinase 3 (PR-3). c IgM. d Latent form of matrix metalloproteinase-9 (proMMP-9). Area under the curve $(A U C)$ is given. An area of 1.0 represents perfect sensitivity and specificity, whereas an area of 0.5 represents random assignment

PR-3 gave a maximum specificity of $92 \%$ and sensitivity of $76 \%$ (Fig. 4), whereas ProMMP-9 gave a maximum specificity of $92 \%$ and sensitivity of $82 \%$ (Fig. 4). Reanalysis of HNP levels from published results [17] also showed improved outcome when normalized to volume or lysozyme concentration (Fig. 4). No significant discrimination power was found for IgM (Fig. 4) or aMMP-9 (data not shown).

\section{Discussion}

Lung transplantation is an effective strategy for the treatment of end-stage lung disease. Unfortunately, chronic rejection remains a major obstacle to long-term survival. This study utilized proteomic approaches, specifically iTRAQ labeling coupled with mass spectrometry, to discover additional disease biomarkers that might provide improved diagnosis and prediction of transplant rejection, and to improve our understanding of disease mechanism. The advantage of iTRAQ labeling is that, in theory, all proteins can be labeled. However, in samples with abundant proteins, such as albumin, these proteins can be disproportionately labeled, and therefore, low abundance proteins are missed. To detect low abundance proteins, samples were subjected to affinity removal of six abundant proteins by a multiple affinity column [18]. This removed a significant proportion of the protein within the BALF. Most individual BALF samples had inadequate protein for individual iTRAQ analysis. The use of pooled samples provided adequate protein. However, this necessitated the validation of discovery by another approach to ensure that results were representative of all the samples and were not biased by outlier values. Peptides from a total of 265 proteins were identified with high confidence. One hundred seventeen proteins were identified by two or more peptides and with satisfactory error factors. Of the 117 proteins, two thirds differed by more than twofold between controls and disease. Some of the proteins have been associated with other severe diseases of the lung, including calgranulin B in pneumonia [19], glutathione S-transferase in lung cancer [20], and PR-3 in acute respiratory distress syndrome (ARDS) [21]. We chose a subset of proteins (MMP9, PR3 , and $\operatorname{IgM}$ ) that were both highly up-regulated and that may be linked to disease mechanism for more detailed analysis.

A peptide of PR-3, a neutral serine proteinase, had the largest fold increase in samples taken at the time of BOS and preBOS. Although PR-3 was represented by a single peptide, it was chosen for further ELISA. PR-3 is capable of degrading such extra-cellular proteins as elastin, fibronectin, and type IV collagen [22-24]. PR-3 is associated with several other lung diseases including Wegener's granulomatosis, cystic fibrosis, and acute respiratory distress syndrome (ARDS) $[21,25,26]$. With regards to mechanism of disease, the highly elevated PR-3 level suggested that proteinase activity may disrupt normal lung tissue structure and play an important role in the development of proliferation and fibrosis of small airways. Furthermore, PR-3 can activate matrix metalloproteinase-2 (MMP-2) and matrix metalloproteinase-9 (MMP-9) [27], another biomarker found in this study.

The iTRAQ data reported over a tenfold increase in the 92-kD proMMP-9 form in disease. We performed ELISA for both the pro- and the active forms. We found a significant increase in the both the pro- and the active forms in disease; however, only the pro-form was elevated before the onset of disease. MMP-9 is a member of the zinc- and calcium-dependent proteinase family that is involved in the degradation and remodeling of the extra- 
cellular matrix. MMP-9 is secreted as a $92-\mathrm{kD}$ pro-form that is cleaved into an $83-\mathrm{kD}$ active form. Metalloproteinases have been associated with many physiological and pathological processes such as cancer, arthritis, wound healing, bone remodeling, atherosclerosis, chronic obstructive pulmonary disease (COPD), lung fibrosis, and lung cancer [27-31]. Moreover, MMP-9 knockout mice are resistant to autoimmune encephalomyelitis and other types of induced inflammation pathologies (e.g., tail pathology) [32]. It has been suggested that MMP-9 may play an important role in the regulation of the immune system in addition to its modulation of the extra-cellular matrix. This function may distinguish MMP-9 from other members of the MMP family [33].

When normalized to total protein, ELISA analysis of lysozyme showed no correlation with progression to BOS. This confirmed a previous study where Clara cell protein in BALF was expressed relative to lysozyme by a mass spectrometry method [16]. The stability of lysozyme allowed it to be used as an internal standard for other biomarkers. Normalizing to lysozyme resulted in a small improvement in biomarker sensitivity and specificity. Total protein was also a biomarker for disease. This was not surprising because increased protein might arise from advancing lung injury that resulted in greater secretion of proteins into the airway. Because BALF protein was elevated in disease, biomarkers normalized to total protein would show lowered sensitivity. It is unlikely that total protein will be a specific biomarker for BOS, as it is likely elevated in many disease states, such as infection, that could affect the allograft. Prospective validation with correction for concomitant diseases will be needed to validate this suggestion. Consequently, normalization of the biomarker concentration to BALF volume resulted in somewhat better outcomes for both the diagnosis and prediction of disease. Whereas the optimum basis for biomarker normalization may be BALF volume, this conclusion should be approached with caution, as protein concentration of BALF may also vary with technical methods.

Overall, chronic lung allograft rejection is a complex, progressive disease that is likely to involve different events and pathways, each of which will be characterized by the up or down regulation of different proteins. A panel of biomarkers may be needed to characterize all pathways and stages of disease. Identification of PR-3 and MMP-9 increased the number of biomarkers of lung transplant rejection and suggested additional factors that may contribute to lung deterioration in chronic rejection and may even provide ideas for therapeutic targets for chronic rejection. This study also provided an illustration of biomarker discovery in pooled samples with subsequent validation by analysis of individual samples with orthogonal technology. The findings illustrated the limitation of pooled sample analysis where up-regulation of IgM was not representative of chronic rejection but was caused by a few extreme outliers. Finally, validation of these biomarkers, alone and in combination, is being conducted as part of a large prospective study that is in progress.

Acknowledgment The authors thank the mass spectrometry core facility at the University of Minnesota, especially Dr. LeeAnn Higgins and Dr. Lori Anderson for their help on mass spectrometry analysis. This research was supported in part by the endowment to the Samuel Kirkwood Professorship (G.L.N.).

\section{References}

1. Trulock EP, Edwards LB, Taylor DO, Boucek MM, Keck BM, Hertz MI. Registry of the International Society for Heart and Lung Transplantation: twenty-second official adult lung and heart-lung transplant report-2005. J Heart Lung Transplant 2005;24 (8):956-67.

2. Burke CM, Theodore J, Dawkins KD, Yousem SA, Blank N, Billingham ME, et al. Post-transplant obliterative bronchiolitis and other late lung sequelae in human heart-lung transplantation. Chest 1984;86(6):824-9.

3. Estenne M, Hertz MI. Bronchiolitis obliterans after human lung transplantation. Am J Respir Crit Care Med 2002;166(4):440-4.

4. Cooper JD, Billingham M, Egan T, Hertz MI, Higenbottam T, Lynch J, et al. A working formulation for the standardization of nomenclature and for clinical staging of chronic dysfunction in lung allografts. International Society for Heart and Lung Transplantation. J Heart Lung Transplant 1993;12(5):713-6.

5. Estenne M, Maurer JR, Boehler A, Egan JJ, Frost A, Hertz M, et al. Bronchiolitis obliterans syndrome 2001: an update of the diagnostic criteria. J Heart Lung Transplant 2002;21(3):297-310.

6. DiGiovine B, Lynch JP III, Martinez FJ, Flint A, Whyte RI, Iannettoni $\mathrm{MD}$, et al. Bronchoalveolar lavage neutrophilia is associated with obliterative bronchiolitis after lung transplantation: role of IL-8. J Immunol 1996;157(9):4194-202.

7. Riise GC, Andersson BA, Kjellstrom C, Martensson G, Nilsson FN, Ryd W, et al. Persistent high BAL fluid granulocyte activation marker levels as early indicators of bronchiolitis obliterans after lung transplant. Eur Respir J 1999;14(5):1123-30.

8. Scholma J, Slebos DJ, Boezen HM, van den Berg JWK, van der Bij W, de Boer WJ, et al. Eosinophilic granulocytes and interleukin-6 level in bronchoalveolar lavage fluid are associated with the development of obliterative bronchiolitis after lung transplantation. Am J Respir Crit Care Med 2000;162(6):2221-5.

9. Meyer KC, Nunley DR, Dauber JH, Meyer KC, Nunley DR, Dauber JH, et al. Neutrophils, unopposed neutrophil elastase, and alpha 1-antiprotease defenses following human lung transplantation. Am J Respir Crit Care Med 2001;164(1):97-102.

10. De Andrade JA, Crow JP, Viera L, Bruce Alexander C, Randall Young K, McGiffin DC, et al. Protein nitration, metabolites of reactive nitrogen species, and inflammation in lung allografts. Am J Respir Crit Care Med 2000;161(6):2035-42.

11. Hertz MI, Henke CA, Nakhleh RE, Harmon KR, Marinelli WA, Fox JMK, et al. Obliterative bronchiolitis after lung transplantation: a fibroproliferative disorder associated with platelet-derived growth factor. Proc Natl Acad Sci USA 1992;89(21):10385-9.

12. Yousem SA, Berry GJ, Cagle PT, Chamberlain D, Husain AN, Hruban RH, et al. Revision of the 1990 working formulation for the classification of pulmonary allograft rejection: Lung Rejection Study Group. J Heart Lung Transplant 1996;15(1 Pt 1):1-15. 
13. Neuringer IP, Chalermskulrat W, Aris R. Obliterative bronchiolitis or chronic lung allograft rejection: a basic science review. J Heart Lung Transplant 2005;24(1):3-19.

14. Wattiez R, Falmagne P. Proteomics of bronchoalveolar lavage fluid. Journal of Chromatography B: Analytical Technologies in the Biomedical and Life Sciences 2005;815(1-2):169-78.

15. Nelsestuen GL, Zhang Y, Martinez MB, Key NS, Jilma B, Verneris $M$, et al. Plasma protein profiling: unique and stable features of individuals. Proteomics 2005;5(15):4012-24.

16. Zhang Y, Wroblewski M, Hertz MI, Wendt CH, Cervenka TM, Nelsestuen GL. Analysis of chronic lung transplant rejection by MALDI-TOF profiles of bronchoalveolar lavage fluid. Proteomics 2006;6(3):1001-10.

17. Nelsestuen GL, Martinez MB, Hertz MI, Savik K, Wendt CH. Proteomic identification of human neutrophil alpha-defensins in chronic lung allograft rejection. Proteomics 2005;5(6):1705-13.

18. Wu J, Kobayashi M, Sousa EA, Liu W, Cai J, Goldman SJ, et al. Differential proteomic analysis of bronchoalveolar lavage fluid in asthmatics following segmental antigen challenge. Mol Cell Proteomics 2005;4(9):1251-64.

19. Buhling F, Ittenson A, Kaiser D, Thölert G, Hoffmann B, Reinhold D, et al. MRP8/MRP14, CD11b and HLA-DR expression of alveolar macrophages in pneumonia. Immunol Lett 2000;71(3):185-90.

20. Benhamou S, Lee WJ, Alexandrie AK, Boffetta P, Bouchardy C, Butkiewicz D, et al. Meta- and pooled analyses of the effects of glutathione $S$-transferase M1 polymorphisms and smoking on lung cancer risk. Carcinogenesis 2002;23(8):1343-50.

21. Merritt TA, Cochrane CG, Holcomb K, Bohl B, Hallman M, Strayer D, et al. Elastase and alpha 1-proteinase inhibitor activity in tracheal aspirates during respiratory distress syndrome. Role of inflammation in the pathogenesis of bronchopulmonary dysplasia. J Clin Invest 1983;72(2):656-66.

22. Rao NV, Rao GV, Marshall BC, Hoidal JR. Biosynthesis and processing of proteinase 3 in U937 cells. Processing pathways are distinct from those of cathepsin G. J Biol Chem 1996;271 (6):2972-8.

23. Borregaard N, Cowland JB. Granules of the human neutrophilic polymorphonuclear leukocyte. Blood 1997;89(10):3503-21.
24. Owen CA, Campbell EJ. The cell biology of leukocyte-mediated proteolysis. J Leukoc Biol 1999;65(2):137-50.

25. Just J, Moog-Lutz C, Houzel-Charavel A, Canteloup S, Grimfeld A, Witko-Sarsat V, et al. Proteinase 3 mRNA expression is induced in monocytes but not in neutrophils of patients with cystic fibrosis. FEBS Lett 1999;457(3):437-40.

26. Hagen EC, Ballieux BE, van Es LA, Daha MR, van der Woude FJ. Antineutrophil cytoplasmic autoantibodies: a review of the antigens involved, the assays, and the clinical and possible pathogenetic consequences. Blood 1993;81(8):1996-2002.

27. Egeblad M, Werb Z. New functions for the matrix metalloproteinases in cancer progression. Nat Rev Cancer 2002;2(3):161-74.

28. Katiyar SK. Matrix metalloproteinases in cancer metastasis: molecular targets for prostate cancer prevention by green tea polyphenols and grape seed proanthocyanidins. Endocr Metab Immune Disord Drug Targets 2006;6(1):17-24.

29. Armstrong EJ, Morrow DA, Sabatine MS. Inflammatory biomarkers in acute coronary syndromes: part IV: matrix metalloproteinases and biomarkers of platelet activation. Circulation 2006;113(9):e382-5.

30. Rouis M. Matrix metalloproteinases: a potential therapeutic target in atherosclerosis. Curr Drug Targets Cardiovasc Haematol Disord 2005;5(6):541-8.

31. Gueders MM, Foidart JM, Noel A, Cataldo DD. Matrix metalloproteinases (MMPs) and tissue inhibitors of MMPs in the respiratory tract: potential implications in asthma and other lung diseases. Eur J Pharmacol 2006;533(1-3):133-44.

32. Dubois B, Masure S, Hurtenbach U, Paemen L, Heremans H, van den Oord J, et al. Resistance of young gelatinase B-deficient mice to experimental autoimmune encephalomyelitis and necrotizing tail lesions. J Clin Invest 1999;104(11):1507-15.

33. Creighton C, Hanash S. Expression of matrix metalloproteinase 9 (MMP-9/gelatinase B) in adenocarcinomas strongly correlated with expression of immune response genes. In Silico Biol 2003;3 (3):301-11.

34. Matecki S, Py G, Lambert K, Peyreigne C, Mercier J, Prefaut C, et al. Effect of prolonged undernutrition on rat diaphragm mitochondrial respiration. Am J Respir Cell Mol Biol 2002;26 (2):239-45. 